\title{
A systematic literature review of pharmacists in general practice in supporting the implementation of shared care agreements (SCA) in primary care
}

\author{
Naveed lqbal ( $\nabla$ n.iqbal6@aston.ac.uk) \\ Aston University https://orcid.org/0000-0003-1807-1424 \\ Chi Huynh \\ Aston University School of Life and Health Sciences \\ lan Maidment \\ Aston University School of Life and Health Sciences
}

\section{Research}

Keywords: Shared care, Pharmacists, Long-term conditions, Systematic review, integrated care, Physicians, Primary Care, Seamless care

Posted Date: February 11th, 2021

DOI: https://doi.org/10.21203/rs.3.rs-215118/v1

License: () (i) This work is licensed under a Creative Commons Attribution 4.0 International License. Read Full License 


\section{Abstract}

\section{Background}

Rising demand for healthcare continues to impact on all sectors of the health service. As a result of the growing ageing population and the burden of chronic disease, healthcare has become more complex, the need for more efficient management of specialist medication across the healthcare interface is of paramount importance. With the rising number of pharmacists working in primary care in clinical roles, is this a role that pharmacist could support to ensure the successful execution of Shared Care Agreement (SCA) in primary care for these patients?

\section{Aim of the review}

Systematic review to identify activities and assess interventions provided by pharmacists in primary care on SCA provision and how it affects health-related quality of life (HRQoL) for patients.

\section{Method}

The following electronic databases were systematically searched from the date on inception to January 2020 : AMED ${ }^{\circledR}, \mathrm{CINAHL} \circledast$, Cochrane Database of

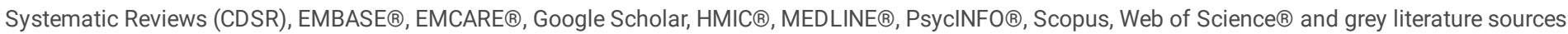
were also searched. The search was adapted according to the respective database-specific search tools. It was searched using a combination of medical subject heading terms $(\mathrm{MeSH})$, free-text search terms and Boolean operators.

\section{Results}

A total of 6,489 titles/abstracts were screened, and 59 full articles were assessed for eligibility. On examination of full text, no studies met the inclusion criteria for this review

\section{Conclusion}

This review highlights the need for further research to evaluate how pharmacists in general practice can support the safe and effective integration of specialist medication in primary care with the use of SCA

\section{Introduction}

Healthcare systems in the world are facing significant challenges as a result of severe funding pressure, a growing ageing population, societal changes, rising demand and a limited supply of some healthcare professional groups [1-3]. This is compounded by the increasing prevalence of long term conditions (LTC), in particular, people having two or more conditions which are being supported by different parts of the healthcare system [4]. The UK is home to the National Health Service (NHS), one of the largest healthcare systems in the world. In the NHS healthcare needs as LTC account for $70 \%$ of the healthcare budget [4] With the continued demands in the NHS the current models of dealing with long term conditions are not sustainable; the need to innovate in order to continue to deliver world-class healthcare outcomes within a limited financial envelope is critical [5]. Care needs to be provided in the right place and the right time to ensure that the healthcare system meets the current and future needs of a nation's healthcare provision [6]. In response to this new normal, care must not be fragmented between healthcare systems, e.g. pre-hospital, hospital and specialist care [7]. This is of particular importance in countries where healthcare systems are well developed where care needs to move seamlessly from the 'gatekeeping' primary care systems to the hospital and specialist services for the benefit of patient care [8]. Effective communication and cooperation between primary and secondary care are critical to making the best use of limited resources [9] and to ensure the patient receives high-quality joined-up care [10-12]. A tool that has been used in the literature to support effective integrated care between primary and secondary care is the shared care agreement (SCA) [13-15]. The SCA was designed to facilitate the passage of hospital prescribed medication or a consultant managed patient into primary care.

The term shared care agreement has various definitions, none of which is universally agreed on [15-19]. The primary description to describe shared care was by Hickman et al. in their seminal paper on the taxonomy of shared care in 1994 [16]. The original definition of shared care described shared care as 'The joint participation of general practitioners and hospital consultants in the planned delivery of care for patients with chronic inflammatory musculoskeletal disorders, informed by an enhanced information exchange over and above the routine clinic, discharge and referral letters'[16]. A more recent evolved definition describes these arrangements as 'the joint participation of primary and speciality care practitioners in the planned delivery of care for patients with a chronic condition, informed by enhanced information exchange, over and above routine discharge and referral notices[17]. This evolved definition takes into account the changes in primary care since the primary definition was described.

Since the introduction of an executive letter EL (91)127 by the NHS in 1991 described SCA to support prescribing between hospitals and GPs [20] several problems have marred the integration of SCA into primary care, and in 2017 the British Medical Association (BMA) stated that shared care is still not working effectively [21]. General practitioners have complained of poor communication between primary and secondary care, lack of follow up and monitoring and the medico-legal responsibilities for the prescriber when they accept shared care [17, 22, 23, and 24]. After 30 years, EL (91) 127 has been superseded by the new national guidance released in 2018 for England [25]. The guidance was designed to overcome the challenges of shared care that have been exhibited in the healthcare system over the last 30 years [22]. The document has described a role for the pharmacist in general practice in supporting joint working and collaboration to ensure that primary care prescribers have access to information on new or less familiar medicines, and how they can support the introduction of medicines into primary care [22]. Evidence indicates that pharmacists have a significant role in medicines optimisation and improve safe and effective 
medication use in primary care [26]. With the support of government initiatives to increase the number of pharmacists in general practice to support new models of care, the pharmacist could be seen a vital component in bridging the transfer of care from secondary to primary care settings $[4,27,28]$.

This paper aims to review the literature on the role of a pharmacist in general practice with regards to SCA support, their roles and identify the potential benefits, barriers and facilitators to their potential integral role.

\section{Aim of the review}

This study aimed to identify activities and assess interventions provided by pharmacists in primary care on SCA provision. The specific objectives were to determine

- The types of interventions/activities being provided by pharmacists in supporting SCA in a general practice setting;

- The effectiveness of these interventions/activities on health-related quality of life (HRQoL) for patients, to consider the impact of clinical pharmacist supporting shared care agreement in a general practice setting.

\section{Method \\ Study registration}

The review protocol was registered with the International prospective register for systematic review (PROSPERO database; registration number CRD42020165363). The review was guided by the recommendations of the Cochrane Handbook for Systematic Reviews of Interventions [29]. The reporting of the review complies with the Preferred Reporting Items for Systematic Review and Meta-Analysis (PRISMA) statement [30].

\section{Eligibility criteria for study inclusion}

The search was focused on locating studies eligible for inclusion or excluded based on the criteria below:

\section{Inclusion Criteria}

1. Only primary studies (qualitative, quantitative and mixed studies);

2. Studies which have tested an intervention and/or have obtained views of stakeholders (pharmacists, GPs, medical specialists, practice staff and patients) related to SCA in the primary care setting.

3. Studies in which a pharmacist has input within a primary care setting to provide non-dispensing care

\section{Exclusion criteria}

1. Studies in which the intervention has been provided only in secondary or tertiary care settings (hospitals, specialist clinics and national and regional specialist centre) ;

2. Studies written in a language other than English;

3. Studies presented as editorials, protocols, and commentaries.

\section{Information sources and search strategy}

The following eleven databases were systematically searched from date of inception to January 2020: Allied and Complementary Medicine Database (AMED $\AA$ ), (1985 to 11.01.2020) Platform: Ovid $\AA$, Cumulative Index to Nursing and Allied Health Literature (CINAHL $®)$, (1950 to 11.01.2020) Platform: EBSCO ${ }^{\circledR}$. Cochrane Database of Systematic Reviews (CDSR), (accessed on 11.01.2020) Platform: Wiley® online library, Excerpta Medica database (EMBASE®), (1974 to 11.01.2020) Platform: Ovid®, EMCARE®, (1995 to 11.01.2020) Platform: Ovid $\AA$, Google Scholar, (accessed on 11.01.2020) Platform: Google UK®, Healthcare Management Information Consortium (HMIC®), (1979 to September 2019) Platform: Ovid ${ }^{\circledR}$, Medical Literature Analysis and Retrieval System Online (MEDLINE®), (1946 to 11.01.2020) Platform: Ovid®. PsycINFO®, Psychology and Behavioural Sciences Collection, Health Business Elite, Biomedica Reference Collection: Comprehensive Library, Information Science \& Technology Abstracts, (1967 to 11.01.2020) Platform: EBSCOhost ${ }^{\circledR}$. Scopus, (2004 to 11.01.2020) Platform: Elsevier, Web of Science ${ }^{\circledR}$ Core Collection, (1970-11.01.2020) Platform: Clarivate Analytics ${ }^{\circledR}$. The search was adapted according to the respective database-specific search tools. It was searched using a combination of medical subject heading terms (MeSH), free-text search terms and Boolean operators. Refer to supplementary information S1 'Search terms' for specific detail of search used for each database. Search results in languages other than English were noted, but for practical reasons, only search results in English, or translated into English, were included in this review. In an effort to identify unpublished studies, a search of grey literature was performed (http://www.opengrey.eu/ on 11.01.2020) to identify studies not indexed in the databases listed above.

\section{Data collection and analysis}


All references from database search were downloaded into Endnote ${ }^{\circledR}$ X8.2 [31] reference manager which was used to collate and remove duplicate records, and to screen titles, abstracts and store the full text of retrieved studies. Citations from OpenGrey could not be uploaded to Endnote $\AA$ reference manager and therefore were uploaded to a Microsoft Excel® 2016 spreadsheet. Duplicate citations were removed by the automatic de-duplicating option in EndNote ${ }^{\circledR}$ X8.2 and were supplemented by hand-searching. Two researchers $(\mathrm{NI})$ and $(\mathrm{CH})$ examined titles and abstracts of all eligible articles according to the inclusion and exclusion criteria listed above. References to be screened were allocated into groups and was divided into 'Include', 'exclude' and 'potential' groupsets. The fulltext articles of any abstracts classified as potentially meeting the inclusion criteria were retrieved and analysed independently by two authors ( $\mathrm{NI}$ and $\mathrm{CH}$ ) against predefined inclusion and exclusion criteria with differences resolved by the research team consensus from the research team. Principal authors of all included papers were contacted to explore the potential for any studies considered vital to them that may have been missed in our search strategy. A data extraction form from the Cochrane collaboration was utilised to extract data from eligible papers [32]. Raw data from qualitative studies were extracted onto Microsoft Excel $\AA^{2} 2016$ spreadsheet.

If data could not be pooled for meta-analysis, the plan was to undertake a narrative synthesis of results. The qualitative data synthesis methodology was decided upon after the quantity, quality, conceptual richness, and contextual thickness of the qualitative studies was determined.

The Mixed Method Appraisal Tool (MMAT) 2018 version was used to appraise and describe the methodological quality of included quantitative, qualitative and mixed-method studies. A pilot test of two articles was conducted to ensure consistent interpretation between the $\mathrm{NI}$ and $\mathrm{CH}$. Discrepancies were resolved through discussion and consensus with the research team. If further information was required to appraise a particular study, an attempt was made to contact the authors by phone or email. Quality scores will be calculated using the MMAT tool. However, this did not solely determine if studies are of "low" or "high" quality, as a descriptive summary using MMAT criteria was considered [33]. If a study received a low score, it was compared with those with a higher score (higher quality studies) to consider if this modifies the outcome and interpretation of our synthesis.

\section{Results}

The database search yielded 6,489 citations. After duplicates were removed, the database search identified 3,231, citations. Based on the information in the title and abstract 3,172 citations met the 'exclude' category, leaving 59 citations identified as 'potential' articles requiring further investigation. 1,336 items were retrieved from http://www.opengrey.eu/. After screening no pertinent articles met the inclusion and exclusion criteria were extracted from grey literature sources.

On examination of the full text of the 59 studies in the 'potential' category, no publications addressing evidence to identify activities and to assess interventions provided by pharmacists in primary care on SCA provision were identified. See table 1 which includes a tabulated list of the 59 excluded studies along with reasons for exclusion, with some articles having more than one reason for exclusion. Out of the 59 excluded studies, one study a conference proceeding could not be found, and an attempt was made to contact the author to obtain further information (full set of results). No response from the author, hence this article was excluded from our review as the reviewers could not assess eligibility based on the information from the abstract. The Preferred reporting items for systematic reviews and meta-analysis PRISMA flow chart below (Fig 1.0) shows the identification, screening, and selection of papers for this review. There were no included studies for which to assess the risk of bias or to apply for evidence synthesis.

\section{Discussion}

The aim of this review was to systematically assess the pharmacist's role in general practice in supporting the implementation of SCA in primary care. No articles met our inclusion criteria. Several studies have previously reported the limited information on a working definition of the role of the pharmacist in general practice $[34,35]$ and second because the general practice pharmacist's role is still a new role in healthcare and little existing literature on role evolution is available[36].

\section{Comparison with other studies}

There is an agreement in the literature that pharmacist role is developing at pace within the general practice setting and recent international systematic reviews and meta-analyses demonstrate positive effects on medication use and clinical outcomes [35, 37]. Pharmacists integrated into general practice teams can perform a variety of roles. This includes direct patient care, medicines reconciliation, and education to members of the healthcare team and in the detection and resolution of medication-related problems [38-40].A recent review of the impact of integrating pharmacists into primary care teams on health systems indicators on healthcare utilisation by Hayhoe et al. 2019 did highlight activities provided by pharmacists in general practice. Still, it failed to discover activities to support SCA in the published literature [41].

The most recent Cochrane systematic review, which assessed the effectiveness of shared care across the interface between primary and speciality care in the management of long term conditions did not consider models of integrating care between pharmacists and primary care physicians [19]. The authors of the Cochrane review stated that this limited its generalisability to all types of collaborative care due to the contextual specificity. The review did note that several other models of shared or collaborative care should be considered for review. This systematic review has highlighted that the model of care involving a pharmacist in primary care supporting SCA is not currently present in the literature and should be considered for further investigation.

\section{Implications of the review findings on clinicians, decision makers in healthcare and future studies}


The changing needs of the population make it increasingly important that the patient's multiple needs are met in a well-coordinated way. To respond effectively to these changing needs, healthcare teams need to utilise the skills available across our healthcare teams. To help alleviate these pressures, it has been recommended that the NHS should maximise the opportunities offered by pharmacists [42-44]. Pharmacists can take on significant amounts of work currently done by GPs and other staff in general practice [44]. To explore whether shared care management could be implemented successfully by the pharmacist in general practice, we need to understand the relevant and important pharmacist related barriers and facilitators concerning the implementation of this role. The influence of these factors needs to be recognised and considered and how this can inform further research into this area.

\section{Decision Making}

Collaboration between pharmacist and the healthcare team is of paramount importance and understanding the skills of multiple healthcare professionals will help support an integrated system [45]. We need to understand the role in which pharmacist will support SCA and how general practitioners are willing to integrate pharmacist within this process. Finding from earlier research has shown that general practice has a positive experience of pharmacist recommendations in a range of conditions [46-48]. However, how would this apply to SCA when patients and healthcare staff need to understand the role of the pharmacist and agree to the SCA? Would patients accept pharmacist undertaking this new role within general practice?

\section{Funding and Workload}

General practice continues to be concerned with the inappropriate funding associated with supporting shared care medication [22]. Commissioners have always stated the funding of specialists drugs has been agreed so cost should not be an issue. General practitioners have expressed concerns that the additional workload required to support the integration of specialised medication is a factor they believe has not been appreciated [49]. This has been exacerbated by the COVID-19 pandemic which has seen a rise in how general practice is expected to manage care which would typically be carried out in hospital setting which in turn has contributed to growing workload in primary care [50]. Previous studies have suggested that the impact of practice-based pharmacists will not be on workload but quality and safety [51]. It is reasonable to ask whether GPs would support pharmacist taking on this role without appropriate funding and whether this intervention will reduce workload in general practice.

\section{Working definition and liability}

We need to consider a working definition of the practice pharmacist role in shared care. The differences in pharmacists' primary care roles have been identified in the international literature. The lack of clarity and knowledge of this primary care role can negatively affected their potential integration into the primary care team [52]. The knowledge, skills, and attitudes required to support SCA should be made readily available to practice pharmacists, primary care teams, and the general public. This would enable SCA management to be developed and applied nationally across primary care. The rapid emergence of new professional roles for pharmacist also means that arrangement in respect of liability needs to keep up with the changing nature of pharmacy practice within this more complex intervention.

This empty review can act as a platform to inform policymakers in health care that there is a lack of robust evidence that evaluates the role and potential value of pharmacist supporting SCA in general practice. Healthcare systems must seek out the best possible evidence to support patients within this new healthcare environment. However, the absence of research in this area does not justify the rejection of this intervention [50]. As the role is a relatively new one, there is still work to be done to develop the evidence base of pharmacists working in general practice to support SCA and benefits of this role within the healthcare system.

\section{Limitations}

A limitation of this review is that the search strategy included a literature search of articles only in the English language. Other articles may have been published on pharmacist supporting SCA in general practice in non-English journals. Personal commentaries, blogs and opinion pieces were excluded from this systematic review due to the research design. This may have excluded observations that are occurring in general practice but have not been critically appraised. Another limitation is that the term SCA may be used as an alternate term from an international perspective. This systematic review used database word stock to establish standard search terms; however, we cannot discount that that this may not have retrieved all articles relating to this intervention. Another limitation that needs to be considered is that abstracts from conference proceedings were not included in the synthesis, which could account for the empty return due to the high evidence bar for the systematic review

\section{Conclusion}

This systematic review identified no eligible studies on the interventions provided by a pharmacist in supporting SCA in general practice. It is not possible to formulate what the role pharmacist can play in supporting SCA in general practice based on scientific evidence. There is an urgent need for studies that identify, observe and evaluate GP based pharmacists roles concerning SCA that currently occur in clinical practice. Comparing and contrasting each general practice's approach will ensure we can develop a consensus for the role of GP pharmacists on SCA based on current SCAs occurring in general practice; and how to implement this intervention consistently. The role of the pharmacist is expanding in general practice and interventions which prove beneficial for patients, and the healthcare system are required to meet the ever-changing demand in healthcare and to ensure that these new interventions follow the evidence. This empty systematic review serves as a starting point for further clinical research in this area.

\section{Abbreviations}


SCA: Shared Care Agreement; HRQoL: Health-Related Quality of Life; MeSH: Medical Subject Heading terms; LTC: Long Term Conditions; NHS National Health Service; BMA: British Medical Association; PRISMA: Preferred Reporting Items for Systematic Review and Meta-Analysis; MMAT Mixed Method Appraisal Tool.

\section{Declarations}

\section{Acknowledgements}

The authors would like to thank Andrew Doyle library specialist at Aston University for his guidance with the development of the search strategy.

\section{Authors' contributions}

$\mathrm{NI}$ was responsible for data collection and contributed to analysis, synthesis, interpretation and project management. He led the drafting of this article. $\mathrm{CH}$ provided methodological, analysis and synthesis input, and contributed to data collection and synthesis. IM contributed to the analysis. NI designed and conducted the searches with support from $\mathrm{CH}$, and contributed to data collection. All authors contributed to revised successive drafts of this article and approved the final version submitted for publication.

\section{Funding}

None

\section{Availability of data and materials}

We provide all supporting data in Supplementary Table 1 and Search Strategy S1.

\section{Ethics approval and consent to participate}

Not applicable.

\section{Consent for publication}

All authors agree with the publication of this article.

\section{Competing interests}

We have no potential conflicts of interest.

\section{References}

1. High-level commission on health employment and economic growth. Working for health and growth: investing in the health workforce. World Health Organization. 2016. http://apps.who.int/iris/bitstream/handle/10665/250047/9789241511308-eng. pdf?sequence=1. Accessed 03 Aug 2020.

2. United Nations Department of Economic and Social Affairs, Population Division. World population ageing 2019 (ST/ESA/SER.A/444). United Nations. 2020. https://www.un.org/development/desa/pd/sites/www.un.org.development.desa.pd/ Accessed 03 Aug 2020.

3. Campbell J, Dussault G, Buchan J, Pozo-Martin F, Guerra Arias M, Leone C, Siyam A, Cometto G. A universal truth: no health without a workforce. Forum Report 2013, Third Global Forum on Human Resources for Health, Recife, Brazil. Geneva, Global Health Workforce Alliance and World Health Organization. 2013. https://www.who.int/workforcealliance/knowledge/resources/GHWA-a_universal_truth_report.pdf?ua=1. Accessed 10 Aug 2020.

4. NHS England, Public Health England, Care Quality Commission, Monitor, NHS Trust Development Authority, Health Education England. NHS five year forward view. NHS England. 2014. https://www.england.nhs.uk/ourwork/futurenhs/. Accessed 10 Aug 2020.

5. Rosen R. Delivering general practice with too few GPs. Nuffield Trust. 2019. https://www.nuffieldtrust.org.uk/files/2019-10/general-practice-without-gpsv2.pdf. Accessed 14 Aug 2020.

6. Jones $\mathrm{R}$, et al. The future of primary and secondary care. Br J of Gen Pract. 2013;63:379-382. doi:10.3399/bjgp13X669400.

7. Scally G, Jacobson B, Abbasi K. The UK's public health response to covid-19. BMJ. 2020; https://doi.org/10.1136/bmj.m1932.

8. Sampson R, Cooper J, Barbour R, Polson R, Wilson P. Patients' perspectives on the medical primary-secondary care interface: systematic review and synthesis of qualitative research. BMJ Open. 2015; https://doi.org/10.1136/bmjopen-2015-008708

9. Naylor C, Alderwick H, Honeyman M. Acute hospitals and integrated care: from hospitals to health systems. King's Fund. 2015. https://www.kingsfund.org.uk/sites/default/files/field/field_publication_file/acute-hospitals-and-integrated-caremarch-2015.pdf. Accessed 26 Aug 2020.

10. Cresswell A, Hart M, Suchanek O, Young T, Leaver L, Hibbs S. Mind the gap: improving discharge communication between secondary and primary care. BMJ Qual Improv Rep. 2015; https://doi.org/10.1136/bmjquality.u207936.w3197

11. Sampson R, Cooper J, Barbour R, Polson R, Wilson P. Patients' perspectives on the medical primary-secondary care interface: systematic review and synthesis of qualitative research. BMJ Open. 2015; https://doi.org/10.1136/bmjopen-2015-008708

12. Epstein RM. Communication between primary care physicians and consultants. Arch Fam Med. 1995;4:403-9. 
13. Integrated care for asthma: a clinical, social, and economic evaluation. Grampian asthma study of integrated care (GRASSIC). BMJ. 1994;308:559-564.

14. Integrated care for diabetes: a clinical, social and economic evaluation. Diabetes integrated care evaluation team. BMJ. 1994;308:1208-1212.

15. Midlands Therapeutics Review and Advisory Committee. Independent review of medicines for primary care.

http://ccg.centreformedicinesoptimisation.co.uk/mtrac/. Accessed 03 Aug 2020.

16. Hickman M, Drummond N, Grimshaw J. A taxonomy of shared care of chronic disease. J Public Health Med. 1994;16:447-54.

17. Horne R, Mailey E, Frost S, Lea R. Shared care: a qualitative study of GPs' and hospital doctors' views on prescribing specialist medicines. Br J of Gen Pract. 2001;51:187-93.

18. Specialist Pharmacy Service. RMOC work programme. NHS England. 2020. https://www.sps.nhs.uk/topics/?with=rMOc. Accessed 03 Mar 2020.

19. Smith SM, Cousins G, Clyne B, Allwright S, O'Dowd T. Shared care across the interface between primary and specialty care in management of long term conditions. Cochrane Database of Systematic Reviews. 2017; https://doi.org/10.1002/14651858.CD004910.pub3

20. National Health Service Management Executive. Responsibility for prescribing between hospitals and GPs. London: NHS Management Executive; 1991.

21. British Medical Association. Primary and secondary care interface guidance. https://www.bma.org.uk/collective-voice/committees/general-practitionerscommittee/gpc-current-issues/nhs-england-standard-hospital-contract-guidance-2017-2019/primary-and-secondary-care-interface-guidance. Accessed 03 Mar 2020.

22. Shared care protocols - have they had their day? Drug Ther Bull. 2017;55:133. https://dtb.bmj.com/content/55/12/133. Accessed 03 Mar 2020.

23. Wilcock M, Rohilla A. Three decades of shared care guidelines: are we any further forward? Drug Ther Bull. 2020. https://dtb.bmj.com/content/58/5/67. Accessed 03 Mar 2020.

24. Crowe S, Cantrill JA, Tully MP. Shared care arrangements for specialist drugs in the UK: the challenges facing GP adherence. Qual Saf Health Care. 2010; https://doi.org/10.1136/qshc.2009.035857

25. NHS England. Responsibility for prescribing between primary \& secondary/tertiary care. 2018. https://www.england.nhs.uk/publication/responsibility-forprescribing-between-primary-and-secondary-tertiary-care/. Accessed 03 Aug 2020.

26. Tan EC, Stewart K, Elliott RA, George J. Pharmacist services provided in general practice clinics: a systematic review and meta-analysis. Res Social Adm Pharm. 2014;608-622. doi:10.1016/j.sapharm.2013.08.006.

27. NHS. The NHS long term plan. 2019. https://www.longtermplan.nhs.uk/. Accessed 03 Mar 2020.

28. Petty D. Clinical pharmacist roles in primary care networks. Prescriber. 2019;22-6.

29. Higgins JPT, Thomas J, Chandler J, Cumpston M, Li T, Page MJ, Welch VA (editors). Cochrane Handbook for Systematic Reviews of Interventions version 6.0 (updated July 2019). Cochrane, 2019. https://training.cochrane.org/cochrane-handbook-systematic-reviews-interventions. Accessed 05 May 2020.

30. Moher D, Liberati A, Tetzlaff J, Altman DG, The PRISMA Group. Preferred reporting items for systematic reviews and meta-analyses: the PRISMA statement. BMJ. 2009; https://doi.org/10.1136/bmj.b2535

31. Clarivate Analytics. Endnote. Version X8.2. Philadelphia, PA: Clarivate Analytics; 2018.

32. Cochrane Effective Practice and Organisation of Care (EPOC). Data collection form. In: EPOC Resources for review authors. Cochrane. 2017. https://epoc.cochrane.org/resources/epoc-resources-review-authors. Accessed 04 Mar 2020.

33. Hong QN, Pluye P, Fàbregues S, Bartlett G, Boardman F, Cargo M, et al. Mixed Methods Appraisal Tool (MMAT), version 2018. Registration of Copyright (\#1148552), Canadian Intellectual Property Office, Industry Canada.

34. Butterworth J, Sansom A, Sims L, Healey M, Kingsland E, Campbell J. Pharmacists' perceptions of their emerging general practice roles in UK primary care: a qualitative interview study. Br J Gen Pract. 2017;67(662):e650-8.

35. Tan, EC, Stewart, K, Elliott, RA, George, J. Pharmacist consultations in general practice clinics: the pharmacists in practice study (PIPS). Res Soc Adm Pharm. 2013;623-32. doi:10.1016/j.sapharm.2013.08.005.

36. Bradley F, Seston E, Mannall C, Cutts C. Evolution of the general practice pharmacist's role in England: a longitudinal study. Br J Gen Pract 2018;68 (675):e727-34.

37. DL, De Gier JJ, de Wit NJ, et al. The degree of integration of non-dispensing pharmacists in primary care practice and the impact on health outcomes: a systematic review. Res Soc Adm Pharm. 2018;14:228-40.

38. Weber ZA, Skelley J, Sachdev G, et al. Integration of pharmacists into team-based ambulatory care practice models. Am J Health Syst Pharm. 2015 May 1;72(9):745-51. doi: 10.2146/ajhp140576.

39. Benson H, Lucas C, Benrimoj SI, Williams KA. The development of a role description and competency map for pharmacists in an interprofessional care setting. Int J Clin Pharm. 2019 Apr;41(2):391-407. doi: 10.1007/s11096-019-00808-4.

40. Benson H, Lucas C, Kmet W, Benrimoj SI, Williams K. Pharmacists in general practice: a focus on drug-related problems. Int J Clin Pharm. 2018 Jun;40(3):566-572. doi: 10.1007/s11096-018-0617-9.

41. Hayhoe B, Cespedes JA, Foley K, Majeed A, Ruzangi J, Greenfield G. Impact of integrating pharmacists into primary care teams on health systems indicators: a systematic review. Br J Gen Pract. 2019;69:e665-74.

42. Naylor C, Alderwick H, Honeyman M. Acute hospitals and integrated care: from hospitals to health systems. King's Fund, March 2015. https://www.kingsfund.org.uk/sites/default/files/field/field_publication_file/acute-hospitals-and-integrated-care-march-2015.pdf. Accessed 18 August 2020

43. NHS England, Public Health England, Health Education England, Monitor, Care Quality Commission, NHS Trust Development Authority. Five Year Forward View. http://www.england.nhs.uk/wp-content/uploads/2014/10/5yfv-web.pdf Accessed 18 August 2020

Page $7 / 9$ 
44. Mann C, Anderson C, Avery A, Waring J, Boyd M. Clinical pharmacists in general practice: pilot scheme independent evaluation report: full report. University of Nottingham. 2018. https://www.nottingham.ac.uk/pharmacy/documents/generalpracticeyearfwdrev/clinical-pharmacists-in-generalpractice-pilot-scheme-full-report.pdf. Accessed 13 January 2020.

45. Reiss-Brennan B, 2 Brunisholz KD, Dredge C, Briot P, Grazier K, Wilcox A, et al. Association of integrated team-based care with health care quality, utilization, and cost. JAMA. 2016;316:826-34

46. Weeks G, George J, MacLure K, Stewart D. Non-medical pre-scribing versus medical prescribing for acute and chronic disease management in primary and secondary care. Cochrane Database Syst Rev. 2016;11:CD01122

47. Anderson C, Zhan K, Boyd M, Mann C. The role of pharmacists in general practice: a realist review. Res Soc Adm Pharm. 2019;15:338-45. Available from: https://dx.doi.org/10.1016/j.sapharm.2018.06.001

48. Raynsford J, Dada C, Stansfield D, Cullen T. Impact of a specialist mental health pharmacy team on medicines optimisation in primary care for patients on a severe mental illness register: a pilot study. Eur J Hos Pharm 2020;27(1):31-5.

49. Nkansah N, Mostovetsky O, Yu C, Chheng T, Beney J, Bond CM, et al.. Effect of outpatient pharmacists' non-dispensing roles on patient outcomes and prescribing patterns. Cochrane Database of Systematic Reviews 2010.

50. Trust GPs to lead: learning from the response to COVID-19 within general practice in England BMA. 2020 Available from: https://www.bma.org.uk/media/2652/bma-report-trust-gps-to-lead-june-2020.pdf Accessed 01 September 2020.

51. Avery AJ. Pharmacists working in general practice: can they help tackle the current workload crisis?. British Journal of General Practice 2017;67 (662):390-1.

52. Jorgenson D, Laubscher T, Lyons B, Palmer R. Integrating pharmacists into primary care teams: barriers and facilitators. Int J Pharm Pract. 2014 Aug; 22(4):292-9. doi: 10.1111/ijpp.12080.

53. Schlosser RW, Sigafoos J. 'Empty' reviews and evidence-based practice. Evid Based Commun Assess Interv. 2009;1-3. doi:10.1080/17489530902801067

\section{Figures}
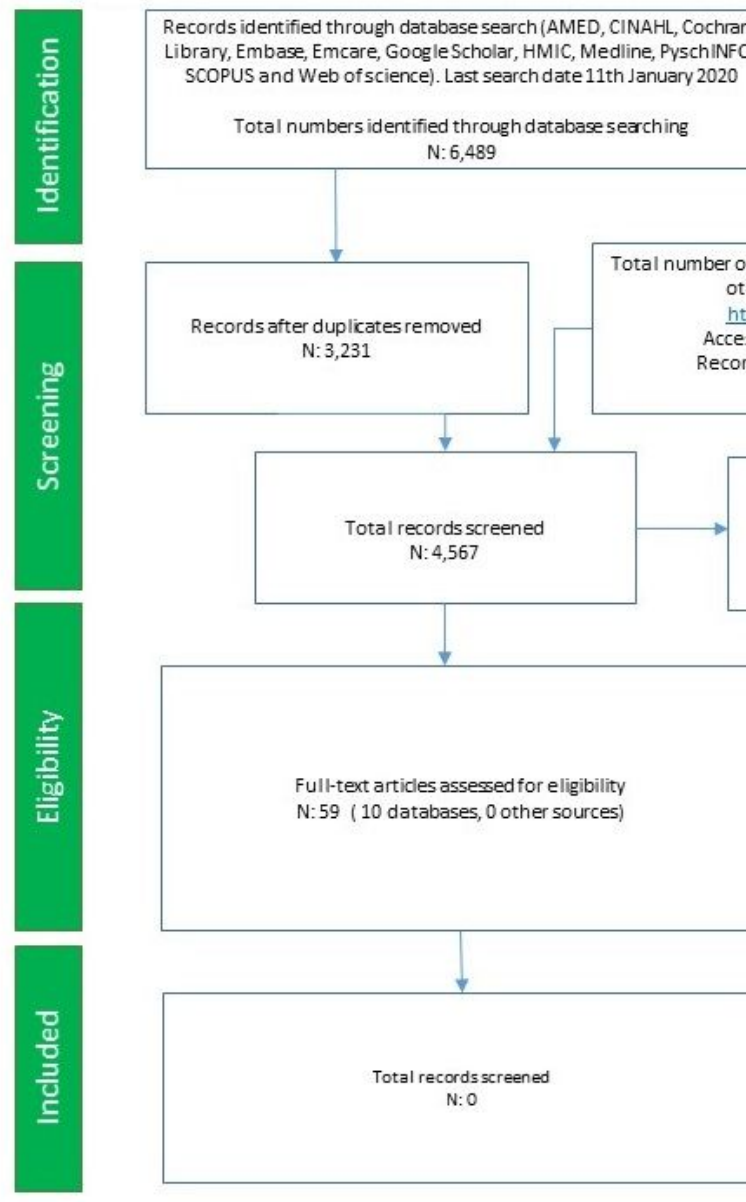

${ }^{a}$ It was not possible to combine and remove duplicates from OpenGrey literature resources because it did not have the option to import results.

\section{Figure 1}

Preferred reporting items for systematic reviews and meta-analyses (PRISMA) flow diagram of screening process and reasons for exclusion of studies

\section{Supplementary Files}


This is a list of supplementary files associated with this preprint. Click to download.

- S1Searchterms.docx

- T1Listofexcludedstudies.docx 